EASTERN REVIEW 2017, T. 6

Сергей Швыдюк

\title{
Состоятельная территориальная община по-украински: теоретическая модель и практика создания
}

В 2014 г. в Украине в рамках провозглашенного курса на децентрализацию власти начались мероприятия административно-территориальной реформы и реформы местного самоуправления. В политическом и управленческом дискурсе эти понятия часто смешивают, или подменяют одно другим.

Отметим, что когда речь идет о децентрализации, то в первую очередь подразумевают передачу значительных полномочий и бюджетов от государственных органов органам местного самоуправления. Так, чтобы как можно больше полномочий имели те органы, которые ближе к людям, и где такие полномочия можно реализовывать наиболее успешно ${ }^{1}$. Под административно-территориальной реформой подразумевают первый этап реформы местного самоуправления и территориальной организации власти. В результате этого появятся дееспособные общины, которым можно передавать необходимый объем полномочий и финансов под их ответственность.

Реформа должна обеспечить реализацию предусмотренного законом «О местном самоуправлении» гарантированного государством права и реальной способности территориальной общины самостоятельно или под ответственность органов и должностных лиц местного самоуправления решать вопросы местного значения в рамках Конституции и законов Украины.

В соответствии с этим законом местное самоуправление в Украине осуществляется территориальными общинами как непосредственно, так и через сельские, поселковые, городские советы и их исполнительные органы, а также через районные и областные советы, представляющие общие интересы территориальных общин сел, поселков и городов. Поэтому в соответствии со

${ }^{1}$ О. Сас, Що таке децеентралізаиія і навіщзо вона всім нам?, http://agropolit.com/blog/48scho-take-detsentralizatsiya-i-navischo-vona-vsim-nam (16.09.2016). 
статьей 2 закона «О местном самоуправлении» под общиной имеют в виду «жителей села или добровольно объединенных в сельскую общину жителей нескольких сел, поселка, города»².

Сформированная в средине 1990-х годов система дистрибуции власти в Украине, в связи с чрезмерной концентрацией ресурсов на центральном уровне, не дает возможности местному самоуправлению в полном объеме исполнять свойственные ему функции. Это осознают как на местном, так и на государственно-управленческом и политическом уровне. Поэтому в Украине после 2004 года предпринимались попытки осуществить административно-территориальную реформу и реформу местного самоуправления, однако, из-за риска для политических элит центра потерять механизмы контроля и рычаги влияния на регионы и местные общины, они оказывались безуспешными. Очередная волна изменений началась в 2014 году с приходом к власти политических элит, приоритетом которых является европейская интеграция Украины. На этот раз Правительство перешло от деклараций к конкретным шагам.

Логика децентрализации подразумевает ряд взаимосвязанных преобразований, призванных в итоге создать новую, более эффективную модель пространственной организации власти и управления в Украине, исходя из принципов субсидиарности. Часть из них можно осуществить путем принятия соответствующих законов и правительственных решений, в то время как ключевые изменения, затрагивающие передачу исполнительных полномочий от местных государственных администраций органам самоуправления - областным и районным советам, требуют конституционных изменений. При этом стоит учитывать тот факт, что эти изменения тесно связаны с проблемой на Востоке Украины, где продолжается Антитеррористическая операция, на самом деле являющаяся противостоянием внешней военной агрессии. В связи с этим временные перспективы принятия необходимых изменений в Конституции по вопросу децентрализации остаются неопределенными.

В начальном этапе реформы должна быть сформирована основа для полноценного функционирования местного самоуправления, способного выполнять свойственные ему функции на надлежащем уровне, и созданы условия для обеспечения этого процесса необходимыми ресурсами. Такой основой станет состоятельная территориальная община. Учитывая сформированную в Украине административно-территориальную и управленческую систему, из существующих почти 12 тысяч общин самодостаточны, то есть реально способны осуществлять полномочия местного самоуправления на

2 Закон Про Місиеве самоврядування в Україні, http://zakon0.rada.gov.ua/laws/show/ 280/97-вр (18.12.2016). 
надлежащем уровне, лишь небольшая часть из них. Как правило, это города и некоторые села. В большинстве же случаев ни пространственных, ни экономических, ни даже кадровых ресурсов недостаточно.

Поэтому реформу местного самоуправления начали с создания состоятельных территориальных общин, под которыми следует понимать «территориальные общины сел (поселков, городов), которые в результате добровольного объединения способны самостоятельно, или через соответствующие органы местного самоуправления, обеспечить надлежащий уровень оказания услуг, в частности в сфере образования, культуры, здравоохранения, социальной защиты, жилищно-коммунального хозяйства, с учетом кадровых ресурсов, финансового обеспечения и развития инфраструктуры соответствующей административно-территориальной единицы» ${ }^{3}$.

С этой целью 5 февраля 2015 г. Верховная Рада Украины приняла закон «О добровольном объединении территориальных общин», а 8 апреля 2015 г. Кабинет Министров Украины утвердил Методику формирования состоятельных территориальных общин. Эти документы предусматривают участие в процессе объединения, как самих общин, так и областных советов, областных государственных администраций, и Правительства. Предусмотрено, что Совет министров Автономной Республики Крым и областные государственные администрации разрабатывают проекты Перспективных планов объединения. Верховный Совет Автономной Республики Крым и областные советы их одобряют, а Кабинет Министров Украины утверждает. И уже на основании утвержденных Перспективных планов осуществляется объединение территориальных общин по процедуре, определенной Методикой. В итоге Центральная избирательная комиссия Украины назначает в них первые выборы, по результатам которых формируются органы местного самоуправления объединенной территориальной общины (ОТО). К очередным местным выборам, состоявшимся в октябре 2015 г. созданы 159 объединенных общин, в состав которых вошли населенные пункты 794 бывших территориальных общин. После декабрьских выборов 2016 г. в Украине уже было 366 объединенных общин, а на 30 апреля 2017 г. назначены первые выборы еще в 47 общинах.

Критерием определения потенциального центра объединенной общины стала доступность от ее центра к периферии. В Методике установлен радиус такой доступности к наиболее удаленной точке, ограниченный 20 километрами по дорогам с твердым покрытием. Расстояние может быть увеличено до 25 километров в случае, если численность населения состоятельной территориальной общины в зоне отдаления от потенциального административ-

${ }^{3}$ Методика формування спроможних територіальних громад. Затверджена Постановою КМУ, від 8 квітня 2015 р. № 214, http://zakon3.rada.gov.ua/laws/show/214-2015$\% \mathrm{D} 0 \% \mathrm{BF} /$ paran10\#n10 (24.10.2016). 
ного центра больше чем на 20 километров составляет не более 10 процентов от общей численности населения общины. Так же расстояние может быть уменьшено в случае отсутствия дорог с твердым покрытием, или в связи с особенностями рельефа, исключающими сообщение (реки без мостов, горы). В то же время зоны доступности потенциальных административных центров состоятельных территориальных общин определяются с учетом доступности услуг в определенных сферах, в частности времени прибытия для оказания скорой медицинской помощи в неотложных случаях и пожарной помощи, не превышающего 30 минут ${ }^{4}$.

Опыт разработки, одобрения и утверждения Перспективных планов, а также объединения территориальных общин в 2015-2016 годах демонстрирует ряд трудностей ${ }^{5}$ О существовании проблем в процессе объединения общин свидетельствует судебная практика по этому вопросу. Как отмечает М. Дзюпын, с марта 2015 г. по март 2016 г. было более 30 судебных исков по делам объединения общин. Их содержание дает основания определить два основных повода таких обращений. Во-первых, нарушения во время проведения общественных обсуждений в процессе добровольного объединения территориальных общин. Во-вторых, нарушения при разработке и утверждении Перспективного плана формирования территории общины ${ }^{6}$. Проблему усматривали в том, что у местных советов и администраций отсутствует традиция обсуждать с жителями важные вопросы, касающиеся жизнедеятельности общин. В свою очередь жители, сомневаясь в способности влиять на решения, тоже не проявляли особенной заинтересованности в таких обсуждениях.

В рамках бюджетной децентрализации с 1 января 2015 г. введены изменения в Бюджетный и Налоговый кодексы, расширяющие финансовые возможности местного самоуправления. Эти изменения направлены на поощрение общин объединяться, поскольку для ОТО с 2016 г. вводились прямые отношения с Государственным бюджетом, без посредничества района и области (по аналогии с городами областного подчинения).

Не мене важным для ОТО стало зачисление в их бюджеты части налогов, а именно: 60\% налога на доходы физических лиц, 10\% налога на прибыль предприятий, акцизного налога, 25\% экологического налога. Кроме

${ }^{4}$ Методика формування спроможних територіальних громад...

${ }^{5}$ С. Швидюк, Створення спроможних громад: українська практика, [в:] Теоретичні, методологічні і практичні проблеми сочіології, історії та політології. Матеріали міжнародної науково-практичної конференції, м. Херсон, 20-21 листопада 2015 р., Херсон 2015, c. $220-223$.

${ }^{6}$ М. Дзюпин, Перший рік об'єднання територіальних громад: судова практика. Аналітична записка, http://samoorg.com.ua/blog/2016/04/05/pershiy-rik-obyednannya-teritorialnihgromad-sudova-praktika/ (16.12.2016). 
того в 2016 году бюджетам ОТО перечислены из государственного бюджета 3,5 миллиарда гривен межбюджетных трансфертов, а на 2017 год предусмотрены 9,6 миллиардов гривен. В связи с этим поступления в общий фонд бюджета этих общин за 2016 год возросли более чем в 6 раз, по сравнению с 2015 годом, а собственные доходы увеличились в 3 раза7 . Такое существенное улучшение финансового положения ОТО создало условия для улучшения социальных и инфраструктурных объектов в общинах и наглядно продемонстрировало целесообразность объединения для других общин.

Создание новой институциональной формы в виде территориальной общины поставило на повестку дня вопрос обеспечения устойчивого и эффективного взаимодействия жителей периферийных населенных пунктов, утративших собственные органы самоуправления с административным центром. Решению этой задачи должно служить внедрение института старосты. Изменениями в закон «О местном самоуправлении» определено, что староста - это должностное лицо местного самоуправления, избирающееся на срок полномочий местного совета в селах, поселках, определенных решением местного совета объединенной территориальной общины, за исключением ее административного центра.

Староста представляет интересы жителей села, поселка в исполнительных органах сельского, городского совета; способствует жителям села, поселка в подготовке документов, подаваемых в органы местного самоуправления; участвует в подготовке проекта бюджета территориальной общины в части финансирования программ, реализующихся на территории соответствующего села, поселка; вносит предложения в исполнительный комитет сельского, городского совета по вопросам деятельности на территории соответствующего села, поселка исполнительных органов сельского, поселкового, городского советов, предприятий, учреждений, организаций коммунальной формы собственности и их должностных лиц; исполняет иные обязанности, определенные Положением о старосте утвержденным советом объединенной общины. По должности староста является членом исполнительного комитета совета объединенной территориальной общины.

Компромиссной нормой закона «О добровольном объединении территориальных общин» стал некий переходной период, на протяжении которого в объединившихся периферийных селах и поселках до проведения первых выборов старосты его обязанности возлагаются на лицо, исполнявшее до этого полномочия сельского, поселкового главы соответствующей территориальной общины. Таким образом, бывшие главы советов получают воз-

7 Фінансово-аналітичні матеріали. Децентралізація. Виконання доходів місиевих бюджетів, 11 місяців 2016 року, http://www.minregion.gov.ua/wp-content/uploads/2016/12/ Ukrayina-OTG.pdf (26.12.2016). 
можность мягкого перехода в статус старосты и шанс позже подтвердить его уже на выборах.

В начале 2017 года в 366 объединенных общинах работали 330 избранных старост и около 1000 исполняющих обязанности старост ${ }^{8}$. Но практика первого опыта работы показала недостаточное регулирование их статуса на законодательном уровне. Проявился широкий диапазон проблем от определения территории, представляемой старостой и до уточнения его полномочий и ответственности. Тщательный анализ опыта функционирования института старост в объединенных общинах и его места в системе управления, проведен экспертами Ассоциации содействия самоорганизации населения9.

Прежде всего, обращалось внимание на неурегулированность процедуры определения общин, в которых избирается староста. По действующему законодательству решение о введении должности старосты в общине принимает соответствующий совет. Но учитывая то, что в составе объединенной общины оказываются бывшие общины, сильно отличающиеся по численности населения, получается, что одни старосты представляют интересы нескольких сотен, а другие - нескольких тысяч жителей. Для исправления такого дисбаланса на законодательном уровне предложили ввести понятие «старостинского округа», под которым понимают «часть территории объединенной территориальной общины, созданной в соответствии с Законом Украины 'О добровольном объединении территориальных общин', на которой размещены один или несколько населенных пунктов (сел, поселков), кроме административного центра объединенной территориальной общины, определенную сельским, поселковым, городским советом с целью обеспечения представления интересов жителей такого населенного пункта (населенных пунктов) старостой» ${ }^{10}$.

Также предусматривается возможность изменять границы старостинского округа по решению совета объединенной территориальной общины. После длительного промедления, необходимые законодательные изменения, определяющие пространственные границы деятельности старост, круг пол-

${ }^{8}$ Старости в селах об'єднаних громад: щчо змінюе новий закон, http://www.minregion. gov.ua/press/news/starosti-v-selah-ob-yednanih-gromad-shho-zminyuye-noviy-zakon-infografika/ (21.02.2017).

${ }^{9}$ О. Колесников, О. Калашнікова, М. Дзюпин, Інститут старост в об'єднаних територіальних громадах: обрання та місие у системі управління, http://samoorg.com.ua/ wp-content/uploads/2016/09/Institut-starost-obrannya-ta-mistse-u-sistemi-upravlinnya-1.pdf (21.02.2017).

${ }^{10}$ О. Колесников, Новий закон щэодо старост - кілька кроків уперед, http://samoorg. com.ua/blog/2016/12/08/zakonoproekt-4742-pro-vnesennya-zmin-do-deyakih-zakonodavchihaktiv-ukrayini-shhodo-statusu-starosti-sela-selishha-v-listopadi-buv-rozglyanutiy-u-profilnomuparlamentskomu-komiteti-ta-pidgoto/ (26.12.2016). 
номочий, основания и порядок их досрочного прекращения, гарантии деятельности приняты парламентом в феврале 2017 года.

Еще одной идентифицированной проблема функционирования института старост оказалось то, что средства на проведение первых выборов старост Государственным бюджетом не предусматривались, более того обязанность их финансирования возлагалась на местные советы. Это создавало риски отсрочки таких выборов по причине отсутствия в местных бюджетах денег на эти цели ${ }^{11}$.

Стоит обратить внимание на то, что в процессе децентрализации резко возросла роль городов, вокруг которых формируются объединенные территориальные общины. Одновременно наметилась тенденция, когда регионы стали блокировать создание общин, тем самым консервируя сельские территории вне влияния городов ${ }^{12}$. В этом контексте можно выделить несколько сдерживающих факторов. С одной стороны города - областные центры чувствуют себя самодостаточными и не заинтересованы в присоединении населенных пунктов. Однако в случае формирования ОТО вокруг таких городов без их участия могут возникнуть трудности в развитии самих городов, поскольку в их границах через некоторое время будет исчерпан ресурс для застройки и размещения объектов инфраструктуры. С другой стороны жители окружающих сел, на самом деле ставших пригородами, тесно связаны с городами, поскольку часто там работают, лечатся или учатся. Вариант выхода из этой ситуации усматривают в создании агломераций ${ }^{13}$. В таком случае отношения между городами и окружающими сельскими населенными пунктами будут осуществляться на основании соглашений о межмуниципальном взаимодействии с сохранением самостоятельного статуса последних. Однако эти предложения пока не получили широкой поддержки.

Следующим сдерживающим фактором для депутатов городских советов и глав городов - областных центров стала их незаинтересованность в новых выборах в случае объединения с окружающими селами. Очередным аргументом против объединения близлежащих сел с областными центрами являются опасения того, что территории сел, вошедшие в объединенную общину будут претендовать на значительную долю общего бюджета, для нужд развития и совершенствования инфраструктуры, тогда как их вклад в бюджет ОТО будет минимальным. В свою очередь села, размещенные вокруг областных центров, опасаются поглощения и перемещения центра принятия решений,

11 О. Колесников, О. Калашнікова, М. Дзюпин, Інститут старост..., с. 15.

12 А. Ткачук, Регіональна політика - два роки иляху (грудневі тези), [в:] Стратегія розвитку. Інформаційний вісник Всеукраӥнської мережі фахівців і практиків з регіонального та місиевого розвитку РЕГІОНЕТ, 2016, грудень, № 1, с. 13.

13 Утворення агломерацій може дати новий поштовх для розвитку громад - В 'ячеслав Негода, http://decentralization.gov.ua/news/item/id/4370 (16.02.2017). 
в первую очередь по земельным вопросам, в советы объединенных общин, где их представительство, а соответственно и вес будут незначительными.

Существовали также трудности и в отношении присоединения населенных пунктов к уже созданным ОТО, прежде всего из за нежелания проводить досрочные выборы совета и главы объединенной территориальной общины. Эту проблему устранили законодательными изменениями, предусматривающими проведение в присоединенных территориальных общинах довыборов депутатов без проведения досрочных выборов главы. Таким образом, в совете новообразованной общины будут представители всех территорий.

К субъективным сдерживающим факторам процессов объединения территориальных общин нужно отнести и то, что в течении длительного времени на уровне районов сформировались местные «олигархи» - влиятельные лица, которым принадлежат достаточно большие хозяйственные активы, а сами они как правило занимали управленческие должности в органах государственной власти, местного самоуправления или имели представительский мандат местных советов разных уровней. Такое сочетание личных интересов с управленческими функциями сделало их своеобразными «хозяевами» районов. К тому же в границах подконтрольных районов сформировался выгодный для них электоральный климат. Из-за этого местные элиты заинтересованы в сохранении status quo, который вероятно будет нарушен в результате формирования в районе нескольких объединенных территориальных общин, возглавляемых новыми лидерами. Поэтому в таких районах продвигается идея объединять общины по формуле один район - одна община. Таким образом, заинтересованные лица рассчитывают сохранить свое влияние.

С другой стороны возникает вопрос о целесообразности существования районов, границы которых полностью совпадают с границами объединенных общин, созданных на их территории. По мнению Первого заместителя Министра регионального развития, строительства и жилищно-коммунального хозяйства В. Негоды «в таких районах исчезают правовые основания для функционирования соответствующих районных советов, представляющих общие интересы территориальных общин сел, поселков, городов, поскольку исключается возможность представления таких общих интересов территориальных общин в связи их фактического отсутствия. Также установление прямых межбюджетных отношений местных бюджетов объединенных общин с Государственным бюджетом обеспечило фактическую передачу всего объема полномочий райгосадминистраций, районных советов соответствующим советам и их исполнительным органам объединенных территориальных общин» ${ }^{14}$.

${ }_{14}$ ОДА спільно з облрадами мають визначитися щяодо доиільності існування районів, межі яких повністю співпадають з межами ОТГ, - В'ячеслав Негода, http://decentralization. gov.ua/news/item/id/3959 (06.06.2017). 
Еще одним источником напряжения способен стать межинституциональный конфликт органов объединенных общин с одной стороны и районных государственных администраций с другой. Примером этого может быть сначала препятствование процессу создания Сторожинецкой ОТО (Сторожинец - районный центр одноименного района в Черновицкой области), а позже сопротивление и саботаж представителей районной власти в ходе формирования управленческих структур объединенной общины и передачи им помещений. Такая ситуация возникает вследствие того, что ОТО создают собственные органы, к которым переходят исполнительные полномочия от райгосадминистраций вместе с ресурсами для их осуществления. И, по мере формирования новых ОТО, территория юрисдикции районных государственных администраций, а также подконтрольные им властные ресурсы, неуклонно сокращаются.

Отметим, что трудности объединения, как и общего прохождения реформы, существуют не только на уровне самих общин, районов или областей, но и на уровне парламента. Об этом свидетельствует затягивание с принятием необходимых для продолжения процесса объединения общин и других реформ местного самоуправления законов, по причине отсутствия поддержи со стороны депутатов. Такое промедление возникает вследствие постоянного отвлечения депутатов на разные политические противостояния, слабости парламентской коалиции и отсутствия политической воли. В итоге медленный темп законодательной деятельности угрожает эффективному проведению реформ.

О недопустимости дальнейших проволочек по этому вопросу свидетельствует настойчивое обращение Представительства ЕС в Украине от 18 января 2017 г. к парламентариям с призывом “принять эти законопроекты без дальнейших поправок, поскольку промедление может затормозить процесс осуществления реформ. Важно, чтобы реформы в этой ключевой сфере продолжались и успешно завершились, без противоречий и задержек"15. К тому, же в обращении был дан четкий сигнал о зависимости дальнейшей поддержки реформ в Украине от принятия необходимых решений - «принятие этих законов станет дополнительным стимулом для иностранных доноров - в их числе и ЕС - в дальнейшем поддерживать реформу децентрализации, предоставлять необходимые средства и делиться опытом» ${ }^{16}$.

Таким образом, можно сделать вывод, что процесс формирования объединенных территориальных общин начался, но его темпы слишком медленны. Это связано как с объективными, так и с субъективными проблемами, возникающими на разных уровнях. Анализ этих проблем и последующее корригирование нормативной базы реформы позволили устранить часть из

15 Позииія Представництва ЄС стосовно законопроектів щодо децентралізації, https:// www.facebook.com/EUDelegationUkraine/posts/1366529516725006 (18.01.2017).

${ }^{16}$ Ibidem. 
них. Другие сдерживающие факторы, особенно субъективные могут быть минимизированы благодаря активной позиции членов и лидеров общин, представителей власти, экспертной среды.

Что касается замедления процесса из-за нежелания самих общин объединяться или неспособности согласования позиций, способных затянуть реформу на неоправданно длительное время, то здесь вероятно, государство использует принудительные меры. В этом контексте И. Колиушко подчеркивает, что «добровольно объединиться всем еще ни в одной стране не удавалось. Поэтому государство должно дать несколько лет на собственную инициативу общинам, а затем завершить реформирование административно-территориального устройства принятием соответствующего закона» ${ }^{17}$.

Успешность процесса децентрализации также будет зависеть от продуманности и скорости проведения реформ в области образования и здравоохранения, поскольку качественные образовательные и медицинские услуги должны предоставляться именно на уровне ОТО, но процесс формирования опорных школ и оптимизация сети лечебных учреждений в 2017 году фактически только начался.

\section{Библиография}

Дзюпин М., Перший рік об'єднання територіальних громад: судова практика. Аналітична записка, http://samoorg.com.ua/blog/2016/04/05/pershiy-rikobyednannya-teritorialnih-gromad-sudova-praktika/ (16.12.2016).

Закон Про Місиеве самоврядування в Україні, http://zakon0.rada.gov.ua/laws/ show/280/97-вр (18.12.2016).

Колесников О., Новий закон щзодо старост - кілька кроків уперед, http:/samoorg. com.ua/blog/2016/12/08/zakonoproekt-4742-pro-vnesennya-zmin-do-deyakihzakonodavchih-aktiv-ukrayini-shhodo-statusu-starosti-sela-selishha-v-listopadibuv-rozglyanutiy-u-profilnomu-parlamentskomu-komiteti-ta-pidgoto/ (26.02.2026).

Колесников О., Калашнікова О., Дзюпин М., Інститут старост в об'єднаних територіальних громадах: обрання та місие у системі управління, http://samoorg. com.ua/wp-content/uploads/2016/09/Institut-starost-obrannya-ta-mistse-u-sistemiupravlinnya-1.pdf (21.02.2017).

Методика формування спроможних територіальних громад. Затверджена Постановою КМУ, від 8 квітня 2015 р. № 214, http://zakon3.rada.gov.ua/laws/show/2142015-\%D0\%BF/paran10\#n10 (24.10.2016).

ОДА спільно з облрадами мають визначитися щзодо доцільності існування районів, межі яких повністю співпадають з межами ОТГ - В'ячеслав Негода, http:// decentralization.gov.ua/news/item/id/3959 (06.06.2017).

\footnotetext{
17 Хаос у законі, „Український тиждень” 2016, № 25(449), с. 25.
} 
Позииія Представниитвва СС стосовно законопроектів щзодо децеентралізаиї, https:// www.facebook.com/EUDelegationUkraine/posts/1366529516725006 (18.01.2017).

Сас О., Що таке децентралізація і навіщуо вона всім нам?, http://agropolit.com/blog/ 48-scho-take-detsentralizatsiya-i-navischo-vona-vsim-nam (16.09.2016).

Старости в селах об 'єднаних громад: щзо змінює новий закон, http://www.minregion. gov.ua/press/news/starosti-v-selah-ob-yednanih-gromad-shho-zminyuye-noviy-zakon-infografika (21.02.2017).

Ткачук А., Регіональна політика - два роки иляху (грудневі тези), [в:] Стратегія розвитку. Інформаційний вісник Всеукраӥнської мережі фахівиів і практиків з регіонального та місиевого розвитку РЕГІОНЕТ, 2016 грудень, № 1.

Утворення агломерачій може дати новий поштовх для розвитку громад - В 'ячеслав Негода, http://decentralization.gov.ua/news/item/id/4370 (16.02.2017).

Фінансово-аналітичні матеріали. Децентралізація. Виконання доходів місиевих бюджетів. 11 місяиів 2016 року, http://www.minregion.gov.ua/wp-content/ uploads/2016/12/Ukrayina-OTG.pdf (26.12.2016).

Хаос у законі, „Український тиждень” 2016, № 25(449).

Швидюк С., Створення спроможних громад: украӥнська практика, [в:] Теоретичні, методологічні і практичні проблеми сочіології, історї та політологї. Матеріали міжнародної науково-практичної конференції, м. Херсон, 20-21 листопада 2015 р., Херсон 2015.

\section{Serhij Szwydiuk}

\section{Sprawna wspólnota lokalna po ukraińsku: model teoretyczny a praktyka budowy}

Artykuł poświęcony jest problemom decentralizacji, dokonującej się na Ukrainie po roku 2014. Analizie poddany został pierwszy etap reformy administracyjno-terytorialnej - reforma samorządu lokalnego i terytorialnej organizacji władz. Na tym etapie tworzone są podstawy pod budowę funkcjonowania pełnoprawnego samorządu lokalnego - sprawnej wspólnoty lokalnej. Pod pojęciem tym rozumie się wspólnoty terytorialne siół (osiedli i miast), które w rezultacie dobrowolnego łączenia się są zdolne samodzielnie lub za pośrednictwem odpowiednich organów jednostek samorządu lokalnego zapewnić członkom wspólnoty odpowiedni poziom usług w zakresie: edukacji, kultury, ochrony zdrowia, pomocy społecznej, gospodarki komunalnej, z uwzględnieniem zasobów kadrowych, finansów, rozwoju infrastruktury w jednostkach administracyjno-terytorialnych. Autor rozważa dotychczasowe osiągnięcia w zakresie łączenia wspólnot terytorialnych i odnotowuje wzmocnienie potencjału finansowego i zasobów w połączonych wspólnotach. Jednocześnie autor zwraca uwagę na szereg obiektywnych i subiektywnych czynników wpływających na tempo reformy. Do czynników obiektywnych zalicza niedoskonałość uregulowań prawnych funkcjonowania nowych instytucji i stosunków, pojawiających się w procesie zmian. Czyn- 
niki subiektywne to przede wszystkim brak woli politycznej po stronie decydentów państwowych, w pierwszej kolejności deputowanych Rady Najwyższej, ale także sprzeciw ze strony elit lokalnych politycznych i administracyjnych. Negatywny wpływ na proces łączenia wspólnot ma stosunek samych wspólnot do proponowanych zmian, a także sprzeczność poglądów w tej sprawie pomiędzy wspólnotami a organami władzy państwowej.

Słowa kluczowe: decentralizacja, reforma samorządu lokalnego, sprawna wspólnota terytorialna, Ukraina.

\section{Serhy Shvydyuk}

\section{Capable territorial communities in Ukrainian style: Theoretical model and creation practice}

The article considers the issues of decentralization, implemented in Ukraine after 2014, and the reforms of local self-government and territorial authority organization in Ukraine as the first stage of the administrative reform. The goal of this stage is creation of capable territorial communities as the basis for the fully functional local self-government. A capable territorial community is a voluntary association of territorial communities of villages (towns, settlements), which is be able to provide the proper level of services, particularly in the fields of education, culture, health protection, social services, housing and communal services, independently or through appropriate local government, in view of human resources, financial provision and development of the infrastructure of the respective administrative-territorial unit. The author considers the intermediate results of the process of association of territorial communities and observes the improvement of financial and resource opportunities in the connected communities. At the same time, he focuses on a number of objective and subjective factors affecting the reforms rate. Objective factors include the lack of legislative regulation of new institutions and relations arising in the process of change. Subjective factors are the lack of political will on the part of decision makers, primarily among the members of Parliament, as well as opposition from local political and administrative elites. Another important factor is the disinclination of the communities to unite or a substantial difference of approach to association between state authorities and communities. Identification and analysis of such factors are important for prognostication and preventing delays in the territorial communities association process, as well as for the implementation of the entire reform.

Keywords: decentralization, local self-government reform, capable territorial community, Ukraine. 